Mayo 2020

\title{
Leer y comprender audiovisuales interactivos: aportes de la lectura detallada y el découpage
}

\author{
Pere Freixa \\ Universitat Pompeu Fabra \\ pere.freixa@upf.edu \\ ORCID: 0000-0002-9199-1270
}

DOI: 10.31009/methodos.2020.i01.03

Freixa, P. (2020). Leer y comprender audiovisuales interactivos: aportes de la lectura detallada y el découpage. En: Lopezosa, C.; Díaz-Noci, J.; Codina, L. (ed.). Anuario de Métodos de Investigación en Comunicación Social, n.1 (p.20-37). Barcelona: DigiDocUniversitat Pompeu Fabra

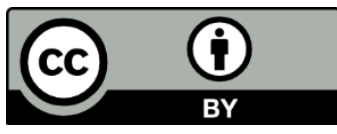





\title{
Leer y comprender audiovisuales interactivos: aportes de la lectura detallada y el découpage
}

\author{
PERE FreiXa \\ Universitat Pompeu Fabra \\ pere.freixa@upf.edu \\ ORCID: 0000-0002-9199-1270
}

\section{RESUMEN}

Desde finales de la década de 1990, autores de ámbitos diversos han producido obras en las que el diálogo interactivo, la multimedialidad y la participación del usuario han permitido explorar las posibilidades narrativas del ecosistema digital. Se trata de textos que ahondan, entre otros, en aspectos como la hipertextualidad, la hipermedialidad y la comunicación bidireccional. Trabajos en los que al usuario se le propone una lectura activa, a menudo complementada con la aportación, creación o co-creación de contenido. La lectura y comprensión de estos textos precisa de procesos de aprendizaje específicos que, lamentablemente, no se recogen en los programas de alfabetización mediática de la enseñanza reglada, ni en la escuela primaria ni en la secundaria. En este artículo se propone una reflexión sobre la lectura detallada de textos audiovisuales interactivos, y se proponen estrategias y herramientas para su comprensión y análisis.

\section{PALABRAS CLAVE}

Lectura detallada, metodología cualitativa, comunicación interactiva, découpage interactivo.

\section{Read and understand interactive digital media: contributions of close reading and découpage}

\section{Llegir i comprendre audiovisuals interactius: aportacions de la lectura detallada i el découpage}

\section{ABSTRACT}

Since the end of the 1990s, authors from diverse areas have produced works in which interactive dialogues, multimedia and user participation have allowed us to explore the possibilities that digital media and networks offer. These texts deepen into aspects such as hypertextuality, hypermediality and bidirectional communication. In these works, the user is offered an active reading, often implemented with the possibility of content contribution, creation or co-creation. The reading and comprehension of these texts requires specific learning processes that, unfortunately, are not included in the media literacy programs of regulated training, nor in primary schools and high schools. This article invites a reflection on close reading of interactive digital media texts and proposes strategies and tools for their understanding and analysis.

\section{KEYWORDS}

Close Reading, Qualitative Methodology, Interactive Communication, Découpage Interactive

\section{RESUM}

Des de finals de la dècada de 1990, autors de diferents àmbits han produït obres en què el diàleg interactiu, la multimedialitat i la participació de l'usuari han permès explorar les possibilitats que ofereixen els mitjans digitals i les xarxes de comunicació. Es tracta de textos que aprofundeixen, entre d'altres, en aspectes com la hipertextualitat, la hipermedialitat o la comunicació bidireccional. Treballs en què es proposa a l'usuari una lectura activa, sovint complementada amb l'aportació, creació o co-creació de contingut. La lectura i comprensió d'aquests textos precisa de processos d'aprenentatge específics que, lamentablement, no es recullen en els programes d'alfabetització mediàtica de l'ensenyament reglat, ni en l'etapa formativa primària ni en la secundària. En aquest article es proposa una reflexió sobre la lectura detallada de textos audiovisuals interactius, i es proposen estratègies i eines per a la seva comprensió i anàlis.

\section{PARAULES CLAU}

Lectura detallada, metodologies qualitatives, comunicació interactiva, découpage interactiu. 


\section{Introducción}

Participar en un videojuego online, consultar una pieza de periodismo estructurado o un webdoc, sólo algunos de los escenarios en los que habitualmente interactuamos con productos que pueden agruparse de forma genérica bajo el epígrafe de audiovisuales interactivos. En ellos, y a menudo, a través de ellos, accedemos a contenidos, nos comunicamos con otros participantes o colaboramos en un proceso informacional.

Cuando se pregunta a usuarios de estas piezas sobre cómo valoran su experiencia, es bastante común que la mayoría de ellos no la conciban como una lectura. Independientemente de si se trata de una pieza textual, consultada a través de una pantalla o de una obra audiovisual más o menos experimental expuesta en un museo, el uso, contemplación o participación de esa obra no presupone que se reconozca que esa experiencia se corresponde con a lectura de texto multimediático e interactivo.

En Rain Room (2012), por ejemplo, la obra-instalación ideada por Hannes Koch, Florian Ortkrass y Stuart Wood y presentada en el Barbican Center de Londres entre octubre de 2012 y marzo de 2013, el usuario experimenta de forma singular su propia presencia en el espacio expositivo mientras contempla y transita la pieza. La pieza se encuentra situada al fondo de una sala en forma de curva. Cuando el público entra en la sala solamente percibe el ruido de la lluvia al caer. Cuando se acerca a la zona de la curva descubre una imponente cortina de agua, de 100 metros cuadrados. El ruido se vuelve ensordecedor. La instalación mantiene una constante lluvia sin fin que el suelo drena inmediatamente después de caer. El público se detiene a contemplar la pieza. Si finalmente una persona decide adentrarse en la lluvia, descubre que el agua se retira, se aparta a su paso. Después de un par de pasos se encuentra rodeado completamente por agua, envuelto por el sonido y olor del aguacero, de la lluvia. Efectivamente, su desplazamiento por el espacio detiene el agua allí donde él está, manteniéndole

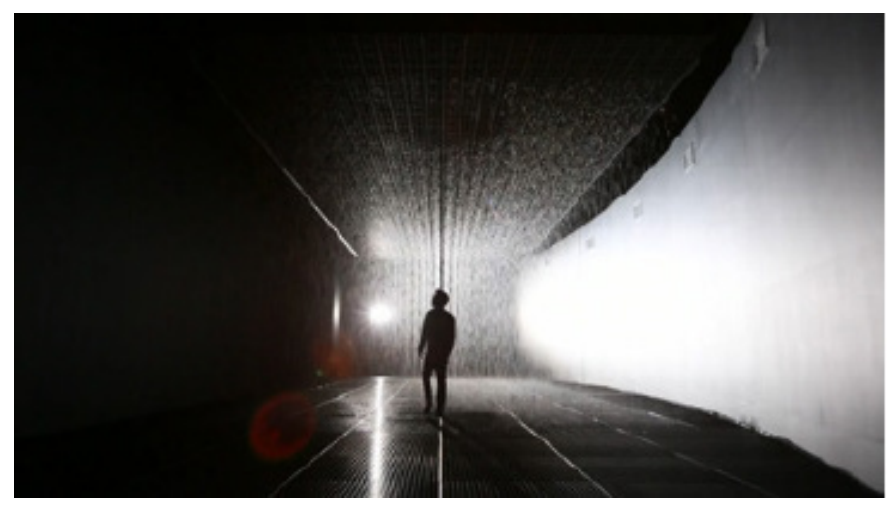

Figura 1. Random International, Rain Room, 2012. Recuperado de: Random International. rodeado y seco de lluvia en todo momento. Sabrina Sweeney (2012) reporta la sensación de empoderamiento que produce la experiencia de la obra, cuando el usuario percibe que controla la lluvia. Se trata de una obra de arte interactiva, más específicamente, utilizando la terminología de Rafaeli (1988), se puede considerar una obra de interacción reactiva, en que el sistema da respuestas pautadas a las acciones de los usuarios.

Mucho antes, en 1988, Luc Courchesne presentaba la pieza Portrait One, que la revista digital Artintact publicaría unos años después (Courchesne, 1995). Se trata de uno de los primeros experimentos de relato hipermedia creado para ser explorado a través de la pantalla. La obra ofrece al espectador un diálogo con Marie, un personaje al otro lado de la pantalla con

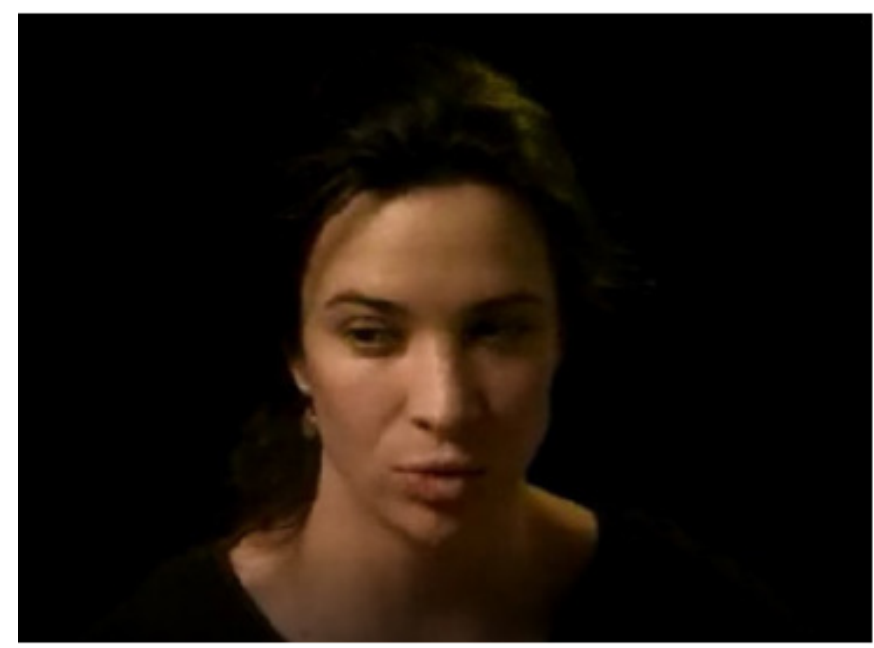

Figura 2. Luc Courchesne, Portrait One, 1990. Recuperado de: Foundation Daniel Langlois.

el que interactuamos y dialogamos. "Portrait One explora el retrato en la era de la hipermedialidad y la realidad virtual (...) En los retratos hipermediáticos, el punto de vista y la actitud del visitante se convierten en una parte intrínseca de la obra, ya que el encuentro entre el artista y el sujeto se vuelve a representar" (Courchesne, 1988). El personaje de Marie, interpretado por Paule Ducharme, increpa al espectador: ¿puedo preguntarte algo? ¿Me estás mirando? las respuestas del espectador llevan el diálogo en una $\mathrm{u}$ otra dirección, en función de las selecciones que éste realice. El texto, el diálogo, empieza y acaba siguiendo distintos recorridos, duraciones e intensidades. Permite un número importante de variaciones y, en consecuencia, de lecturas y significados.

Chris y Laura Amico pusieron en marcha el proyecto Homicide watch D.C. (2010), un proyecto de periodismo estructurado (Freixa, Pérez-Montoro, Codina, 2017) en el que se recogen todos los casos de asesinato que se dan en el distrito de Columbia, en Estados Unidos. Utilizan informes originales, 
documentos judiciales, publicaciones de redes sociales y los aportes de familiares y conocidos de las víctimas y sospechosos. El equipo de Homicide watch D.C. añade información periodística relacionada con cada caso. "Como residentes de DC, creemos que la forma en que las personas viven y mueren aquí, y cómo se reconocen esas muertes, importa a cada uno de nosotros (...) Si queremos entender los delitos violentos en nuestra comunidad, las pérdidas de cada familia, en cada vecindario, deben ser reconocidas" (Amico, Amico, 2011). Tanto ciudadanos anónimos como periodistas pueden acceden a Homicide Watch para informarse, participar o, simplemente, comprobar la seguridad del barrio de su escuela.

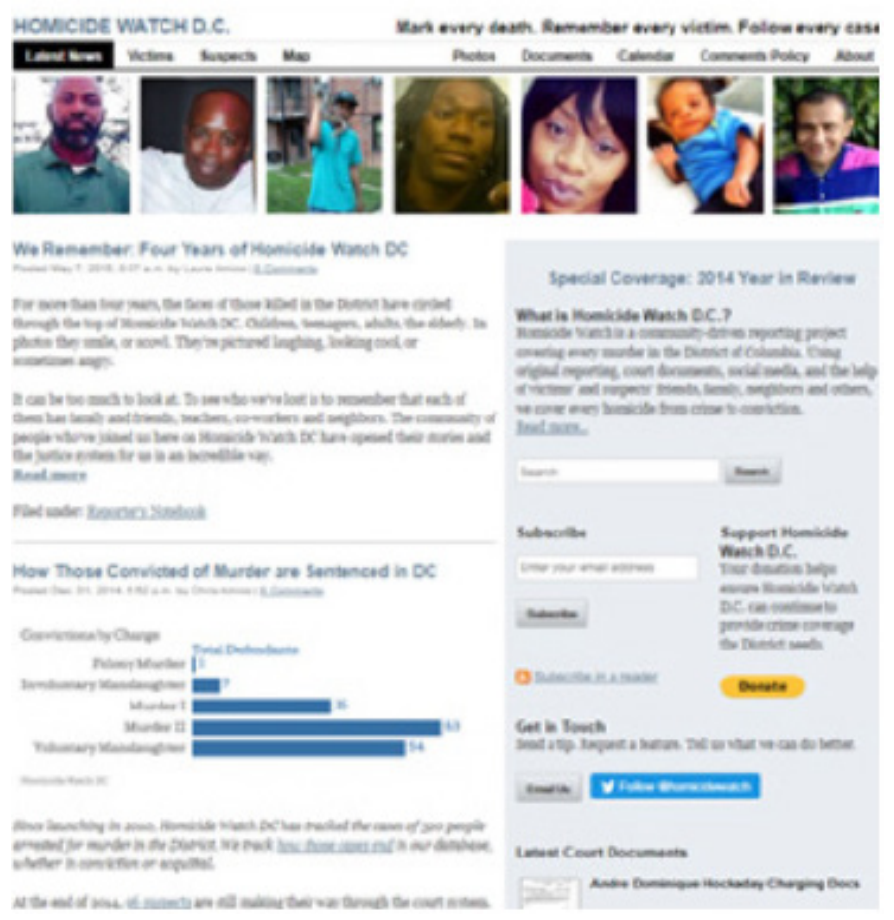

Figura 3. Homicide Watch D.C. Recuperado de: http:// homicidewatch.org/index.html

Portrait One, Homicide watch y Rain Room comparten, a pesar de las muchas distancias que podemos observar en ellas, elementos en común. Las tres obras pueden considerarse textos multimediáticos e interactivos, o utilizando la terminología acuñada por Aarseth, cibertextos, que precisan de una praxis de lectura específica: "El lector de cibertextos es un actor, un jugador; el cibertexto es un mundo de juego o un juego del mundo; es posible explorar, perderse y descubrir caminos secretos en estos textos, no metafóricamente, sino a través de las estructuras topológicas de la maquinaria textual (...) Cybertexto es una perspectiva que utilizo para describir y explorar las estrategias comunicacionales de los textos dinámicos». (Aarseth, 1997, p. 4-5).

Ante la evidencia de la emergencia de nuevas praxis, así como de mecanismos y procedimientos de significación también en constante transformación, la reflexión sobre el texto, sobre los textos, se presenta como oportunidad para redefinir en qué consiste la lectura. Con ello se recupera la posibilidad de volver a focalizar el análisis de contenido en las obras. Supone reconocer la capacidad del texto mediático por "presentar un momento discursivo distintivo entre la codificación y la decodificación que justifica un especial compromiso académico." (Fürsich, 2009, p.238). Los textos suponen un lugar de encuentro en el que se concretan las múltiples posibilidades de comprensión y significación que el texto propone desde la potencialidad. A diferencia de los análisis realizados desde la significación, que codifican los textos en una determinada direccionalidad, la que el usuario le atribuye, plantear el texto audiovisual interactivo como posibilidad permite abordarlo asumiendo la multiplicidad de lecturas que de él se pueden formular.

\section{Antecedentes}

\subsection{La tradición del close reading}

Des de finales de los años treinta del siglo pasado, la crítica literaria primero y el estudio de los medios posteriormente, desarrollaron un método de análisis de texto detallado, conocido como close reading, consistente, según Bizzocchi y Tanenbaum en un "examen detallado, de la deconstrucción y análisis de un texto mediático. Es la metodología humanista por excelencia, nacida en el estudio de la literatura y adaptada a otras formas de medios, como los estudios de cine." (2011, p. 289). No existe una traducción precisa para el término en español; lectura detallada, lectura minuciosa, lectura en profundidad son algunas de las expresiones utilizadas en lengua castellana para referirse al close reading. Todas ellas aportan matices al significado del término. En esta investigación se ha utilizado principalmente el término lectura detallada, aunque puntualmente se ha optado por las otras formas cuando se ha querido poner en valor algún matiz específico.

La centralidad del texto como elemento de análisis para la crítica y estudio de los contenidos culturales ocupa un lugar hegemónico en los métodos de análisis desde la implantación de la semiótica y el posestructuralismo, considerando cualquier práctica cultural como texto, es decir, como elemento susceptible de ser aislado y analizado desde una óptica de lectura. Sin embargo, las revisiones posmodernas iniciadas en la década de los 70 s y 80 s del pasado siglo y la influencia de la sociología y los estudios culturales han cuestionado la centralidad del análisis de texto como base de la crítica y concepción de los estudios sobre los medios y han desplazado el interés analítico en las metodologías basadas en la recepción, 
justificando el proceso de significación en el medio y el usuario.

Recientemente, algunos autores, como Fürsich, plantean la necesidad de retornar al análisis textual en el estudio de los medios. Afirma que "Sólo el análisis textual independiente puede dilucidar la estructura narrativa, la disposición simbólica y el potencial ideológico del contenido de los medios." (2009, p. 239). Más allá del trabajo fundacional de Aarseth (1997), Van Looy y Baetens pueden considerarse pioneros en aplicar técnicas de análisis detallado a los textos digitales en su obra seminal Close Reading New Media (2003).

¿En qué consiste esta categoría de análisis detallado? ¿Para qué sirve? y, quizás más importante, ¿cómo se aplica? El sistema educativo norteamericano recoge por medio del Common Core State Standars (2019) el conjunto de competencias vinculadas al aprendizaje y comprensión de texto que el alumnado debe adquirir al finalizar la educación secundaria (17 años). En este sistema educativo, el close reading se postula como la herramienta pedagógica fundamental para la obtención de dichas competencias. "La lectura en profundidad permite el análisis crítico y reflexivo del texto. Se centra en localizar detalles y patrones significativos a partir de los cuales se desarrolla una comprensión profunda y precisa de los elementos formales, el estilo y los significados del texto" (Burke, 2012, p.2). Con él se analizan tanto aspectos cuantitativos, codificados en el sistema de niveles llamado Lexile (Lexile, 2019), como cualitativos: relacionados con la estructura del texto, propiedades del lenguaje o el estilo del autor, entre otros (Lapp et al., 2015).

Los defensores de la lectura detallada aplicada a los textos audiovisuales tienen en Cavell uno de sus mayores referentes. Para él, el análisis detallado de un film permite la observación minuciosa de aquellos aspectos del texto capaces de ofrecer significación: "Lo que debemos apreciar es la inteligencia que una película ya ha concentrado en su realización" (Cavell, 1999, p.20). Añade: "Nuestra tarea crítica consiste en descubrir por qué pasan el tiempo como lo hacen [los personajes], por qué dicen lo que dicen. Sin centrarnos en los detalles de las películas, no podemos esperar saber qué son, saber qué las causa" (1999, p.16).

El análisis de obras concretas permite a Cavell establecer una definición de los géneros y medios basada en tres aspectos, como recogen y reformulan Van Looy y Baetens (2003). En primer lugar, se constata como un género no puede ser considerado como tal sin la existencia de unos primeros texto que permita definirlo. Los géneros y medios se establecen a partir del análisis de obras concretas. En consecuencia, un medio no existe antes de que una primera obra lo incorpore, ya que, en ese caso, existiría como abstracción, como constructo virtual. En tercer lugar, Cavell concluye que los medios que esas obras permiten definir existen cuando los elementos formales se vuelven significativos y permiten una determinada significación.

¿De qué forma debemos acercarnos a los textos audiovisuales interactivos? ¿Qué elementos debemos destacar, qué detalles nos permitirán establecer las pautas que permitan su comprensión y clasificación? y, en consecuencia, ¿qué características permiten diferenciar estos textos de otros medios audiovisuales?

\section{2. el découpage de interactivos}

En trabajos anteriores (Freixa, 2009; 2015; Freixa et al., 2014) se expuso la herramienta titulada découpage interactivo, un sistema de análisis que permite una observación minuciosa de los principales elementos que configuran un audiovisual interactivo. El proceso de observación se propone "la obtención de una descripción detallada de los elementos básicos que conforman las aplicaciones audiovisuales interactivas con el fin de restituir, en última instancia, un símil del guión que las generó" (Freixa et al., 2014, p.4).

El propósito inicial de esta metodología de observación responde a la voluntad de acercar la lectura al proceso de elaboración de guión y diseño de piezas y obras interactivas. Busca crear un espacio de encuentro entre la formalización de los proyectos, en forma de guiones técnicos, diseños y diagramas con la Lectura, la comprensión de las mismas por medio de la restitución. Forma parte del conjunto de herramientas desarrolladas por el Área de Comunicación Interactiva del Departamento de Comunicación de la Universitat Pompeu Fabra para el aprendizaje del diseño de interacción, una especialidad aún emergente resultado de la irrupción de la comunicación digital interactiva (Ribas y Freixa, 1997; Ribas, 2001; Soler, et. al., 2016), especialmente en el ámbito de la comunicación social, el periodismo y la experimentación cultural.

Se trata de un procedimiento basado en dos fases. Una primera, descriptiva y de identificación, en la que se recogen los elementos básicos que permiten la comprensión literal del texto, así como la codificación de sus aspectos más destacados. En una segunda fase, se sigue una lectura detallada en profundidad de toda la pieza, considerando 4 apartados: contenido, estructura, interfaz e interacción. Se analizan las piezas por medio de indicadores parametrizados en valores. Estos pueden ser tanto numéricos como textuales. Cada uno de estos cuatro apartados permite la recreación de un documento similar al realizado pro los autores de la obra durante el proceso de guión y producción. 
La universalización de los medios interactivos, sobre todo como resultado de la expansión de los dispositivos móviles y las redes sociales, permite revisar la herramienta del découpage interactivo para adaptarlo a nuevas funcionalidades, como se propone ahora, básicamente relacionadas con la alfabetización mediática. Sin perder su potencial para emular el proceso de guión y elaboración de productos interactivos, la herramienta puede reformularse para devenir soporte de aprendizaje para la lectura de esos medios interactivos. Su diseño modular permite tanto la incorporación de nuevos módulos como la aplicación fragmentada de los mismos, en función de posibilitar la observación detallada de determinados aspectos de las piezas analizadas.

\subsection{Lectura detallada y juegos digitales}

Van Looy y Baetens (2003) fundamentan el análisis detallado de textos interactivos basándose en aportaciones fundacionales del ámbito de la comunicación interactiva. Retoman de Ryan (2001) la dualidad inmersión versus interacción. Se trata de una polaridad que permite definir la virtualidad, como un medio que oscila entre la inmersión, entendida como recreación de un universo envolvente, de tradición literaria, y la interacción, asociada al juego, que atribuye al usuario la posibilidad de actuar. El equilibrio entre ambos aspectos permite la clasificación de piezas y la emergencia de la comunicación virtual interactiva, el relato virtual. Sus trabajos, sin embargo, analizan básicamente obras hipermedia en las que el texto juega un papel determinante.

El análisis detallado también se ha intentado implementar en el estudio de los videojuegos. Los aportes desde este ámbito son especialmente significativos, ya que permiten contemplar dimensiones del usuario, del texto y del proceso de significación desde ejes novedosos respecto a la tradición hipertextual del análisis de interactivos. Brooker (2001); Consalvo y Dutton (2006); Carr (2009); Bizzocchi y Tanenbaum (2011), entre otros, han planteado la lectura crítica de juegos digitales, tanto de video juegos como de juegos para computadora $\mathrm{u}$ otros dispositivos. Brooker (2001), plantea una primera aproximación al análisis de juegos digitales contemplando aspectos específicos de los videojuegos. Los dos primeros corresponden a aspectos contextuales a la experiencia del juego, como son su naturaleza comercial, en tanto productos de la industria de las consolas y los videojuegos (análisis institucional) y su autoría. Brooker aporta información sobre el diseño y el grafismo de los elementos visuales, así como de la programación del juego (análisis de autoría). En tercer lugar, analiza los elementos narrativos y los personajes que contiene el juego (personajes y narrativa) en comparación con otros juegos, lo que permite una suerte de análisis comparado. Finalmente analiza aspecto relacionados con el género y el discurso (género y connotaciones sociopolíticas).

Consalvo y Dutton (2006) plantean la necesidad de establecer una herramienta metodológica que permita el estudio cualitativo de los juegos digitales organizada en cuatro áreas: Inventario de objetos, estudio de la interfaz, mapa de interacción y registro del juego. El análisis se plantea a partir de la realización de preguntas de investigación previas a la lectura del juego, acorde con la tradición del análisis detallado. Quizás el aporte más significativo de este modelo radica en la consideración que presentan los autores sobre la dificultad, por no decir la imposibilidad, de realizar, durante el análisis, todas las lecturas posibles del texto. Efectivamente, recorrer todas las posibilidades de un videojuego o un interactivo de cierta complejidad puede suponer una tarea de centenares de horas. Esto afecta a la comprensión de aquellos aspectos mas condicionados por la propia dinámica del juego, como son la emergencia de significación o la compleción de recorridos.

Carr (2009) plantea el análisis de videojuegos tomando en consideración un sistema de análisis basado en la superposición de tres marcos de interpretación: el marco estructural, la textualidad y la intertexualidad, todos ellos ámbitos de análisis derivados de Roland Barthes. El modelo de Carr parte de la concepción del texto como sistema, como conjunto de elementos relacionados entre ellos que forman una unidad compleja. En 2011 Bizzocchi y Tanenbaum aportan una importante reflexión sobre el rol del analista en la observación de una obra digital interactiva. Apuntan cuatro aspectos a considerar cuando se afronta el análisis de un texto complejo como puede ser un juego digital, como son la indeterminación, el alcance, la dificultad y la oscilación.

La indeterminación se presenta ante la imposibilidad de poder establecer que dos lectores distintos se encuentren con los mismos recursos y orden de experimentación. Es por ello que "en un texto digital, la lectura debe poder explicar la naturaleza indeterminada de la experiencia" (Bizzocchi, Tanenbaum, 2011, p.7). Es importante remarcar que la indeterminación no debe confundirse con a la interpretación. La indeterminación permite la incorporación de la expectativa como hipótesis de significado. En casos extremos, como en juegos en línea de multijugador, u obras colaborativas, el objeto incorpora potencial de dinámicas sociales más allá de lo que los autores hubiesen anticipado. En consecuencia, puede afirmase que la indeterminación del texto digital permite la incorporación de la noción de emergencia como potencialidad (Soler-Adillon, 2015). Ciertamente, en los mundos virtuales y en el análisis de complejas obras transmedia, para algunos autores la lectura detallada a menudo se asemeja a 
las prácticas de la auto-etnografía y la observación participante.

El alcance, como ya apuntaron Consalvo y Dutton (2006), refiere a la imposibilidad de experimentar el texto de forma completa en todas sus posibles variantes. Esta limitación, inexistente en cualquier otra forma de texto analizada por medio de la lectura detallada, caracteriza a los relatos digitales interactivos. Algunas piezas interactivas, como juegos de rol, periodismo estructurado o relatos transmedia, pueden precisar de centenares de horas para completarlas. Otras obras, de menor dimensión, contemplan la repetibilidad como característica: hay niveles sólo alcanzables después de conseguir determinados hitos, así como cambios para adaptarse al nivel alcanzado por el usuario.

Este aspecto caracteriza la dificultad, que presenta dos dimensiones: la necesidad de habilidades por parte del lector y la dificultad de la propia experiencia en sí, como parte de un desafío analizable en tanto guión. El binomio dificultad-habilidad constituye un reto para los autores y determinará el interés y satisfacción del usuario, el flujo del juego (Csikszentmihalyi, 1990) así como la capacidad de observación y lectura de los distintos elementos y desafíos. La dificultad y habilidad condicionan la capacidad analítica del observador/usuario, que puede ver limitada su aproximación al texto.

Finalmente, la noción oscilación aporta reflexión sobre el rol del investigador que se enfronta al análisis y lectura de un interactivo digital de cierta complejidad. Refiere a la dualidad de roles que debe desarrollar el investigador, quien debe mantiene dos niveles de atención cognitiva. Por un lado, debería actuar como "jugador naif", como principiante, con la finalidad de mantener entrega incondicional a la experiencia. Simultáneamente, como académico o analistas, debe distanciarse de la experiencia para poder "experimentar el juego en estado de hipermediación, consciente del hecho en sí de la mediación" (Bizzocchi, Tanenbaum, 2011, p.7).

\section{Lectura detallada y découpage interactivo. Hacia un modelo de análisis abierto}

Como apunta Burke, la lectura en profundidad o detallada, el close reading, como recurso pedagógico se diferencia de la lectura guiada y otros métodos de aprendizaje porque, justamente, la lectura detallada no es un método de enseñanza. "La lectura detallada sirve para extraer significado del texto mismo, para comprender lo que el autor está tratando de decir (...) El texto no se selecciona en función de la legibilidad, sino de la complejidad de las ideas para explorar" (Burke, 2015). Las lecturas se preparan con anterioridad, se seleccionan fragmentos significativos $\mathrm{y}$ se lee y relee el texto varias veces. Con ello se consigue profundizar sobre su contenido, así como reflexionar sobre el propio proceso de obtención de significado. Para algunos autores, la lectura minuciosa y detallada de este sistema de análisis propensa, más allá de la indeterminación, la interpretación y la exegesis, con el peligro implícito que supone de recreación y sobreinterepretación. Sin embargo, la aplicación de una explícita sistemática facilita la ubicación del analista en relación con el texto y con los objetivos de análisis especificados.

Tanto la propuesta de découpage interactivo desarrollada en trabajos preliminares como la mayoría de los trabajos examinados en el presente estudio plantean la utilidad del análisis organizado y realizado por pasos, por medio de lecturas sucesivas, cada una de ellas de mayor precisión y con un objetivo preciso. En la primera lectura, como se ha expuesto anteriormente, se reconoce de forma global la pieza analizada y se recogen los elementos básicos que permiten su comprensión literal y así como la codificación de sus aspectos más destacados.

Par los propósitos de este trabajo, proponemos una actualización del modelo previo de découpage interactivo en el que se incorporan elementos propios de la lectura detallada. Como se ha mencionado, el análisis se realiza a partir de un sistema pautado formado por un conjunto de indicadores. Estos pueden ser diversos: textuales, numéricos o gráficos. Para cada indicador se establecen los valores y códigos que lo caracterizan y delimitan. En la primera fase se propone complementar el módulo inicial, módulo descriptivo, compuesto por 35 indicadores organizados en tres apartados: autoría y dispositivo de análisis, datos identificativos y descripción y comprensión general.

El autor del análisis acostumbra a realizar una primera lectura general y superficial de la obra y retorna al texto para complementar los distintos apartados de la ficha. Se trata de una primera fase con voluntad descriptiva, lo más objetiva posible, en la que se recomienda no entrar aún en los aspectos discursivos e ideológicos del texto. Se aconseja cumplimentar, en cada caso, aquellos apartados que se consideren significativos y prescindir de los que no procedan o no aporten interés. Para algunos apartados, como los 1.2.01.2 o 1.2.02.2, se precisa la consulta del código de programación con el que se ha codificado el texto, por medio de las herramientas que los navegadores permiten. 
Tabla 1. Módulo descriptivo. Apartado 1.1 Autoría y dispositivo de análisis

\begin{tabular}{|c|c|c|c|}
\hline \multicolumn{4}{|c|}{ 1. Módulo descriptivo } \\
\hline \multicolumn{4}{|c|}{ 1.1 Autoría y dispositivo de análisis } \\
\hline CODIGO & INDICADOR & VALOR & DESCRIPCIÓN Y/O PROCEDIMIENTO \\
\hline 1.1 .01 & Fecha de análisis & [dd/mm/aaaa] & Indicar la fecha de realización del análisis \\
\hline 1.1 .02 & Autoría & [texto] & Nombre y datos identificativos del autor \\
\hline 1.1 .03 & Filiación & [texto] & Centro, empresa o entidad del autor \\
\hline 1.1 .04 & Programa & [texto] & $\begin{array}{l}\text { Indicar si el análisis forma parte de un } \\
\text { proyecto o programa específico }\end{array}$ \\
\hline 1.1 .05 & Dispositivo/s & [texto] & $\begin{array}{l}\text { Modelo/s de dispositivo utilizado para } \\
\text { el análisis. Según el texto que se analice, } \\
\text { el uso de un u otro dispositivo puede } \\
\text { condicionar enormemente la presenta- } \\
\text { ción y desarrollo narrativo de la obra }\end{array}$ \\
\hline 1.1 .06 & $\begin{array}{l}\text { Sistema operativo } \\
\text { y navegador }\end{array}$ & [Texto] & $\begin{array}{l}\text { Sistema operativo, programa de navega- } \\
\text { ción y versiones utilizadas para el análisis }\end{array}$ \\
\hline 1.1 .07 & $\begin{array}{l}\text { Capacidades } \\
\text { requeridas }\end{array}$ & [texto] & $\begin{array}{l}\text { Indicar si se precisa la instalación } \\
\text { de programas o plugins para la } \\
\text { recepción y lectura de la pieza o } \\
\text { si se precisan determinas capaci- } \\
\text { dades de procesado o dispositivo }\end{array}$ \\
\hline 1.1 .08 & Otras versiones & [texto] & $\begin{array}{l}\text { Indicar si el producto dispone de } \\
\text { versiones alternativas para otros } \\
\text { dispositivos o sistemas operativos }\end{array}$ \\
\hline 1.1 .09 & Localización & [Texto] & Lugar en el que se realiza el análisis \\
\hline 1.1.10 & $\begin{array}{l}\text { Contexto de } \\
\text { lectura }\end{array}$ & [Texto] & $\begin{array}{l}\text { Indicar en qué situación se realiza } \\
\text { el análisis: en un aula, individual- } \\
\text { mente, en equipo, etc. }\end{array}$ \\
\hline
\end{tabular}

Para usos particulares, se puede prescindir de los indicadores de 1.1.01 hasta 1.1.04. Se considera importante, sin embargo, tomar en consideración las repercusiones sobre el texto de aspectos como el dispositivo, la versión consultada, el lugar de lectura o el contexto. La comprobación de otras versiones, así como las limitaciones técnicas de los productos ofrecen datos importantes sobre la posible obsolescencia de los mismos, público potencial, adaptabilidad y previsión de vida de los productos.

Tabla 2. Módulo descriptivo. Apartado 1.2 Datos identificativos

\section{Módulo descriptivo}

\subsection{Datos identificativos}

\begin{tabular}{|l|l|l|l|}
\hline 1.2.01.1 & Título & [Texto] & $\begin{array}{l}\text { Título del producto que aparece en la } \\
\text { cabecera o página principal del interactivo }\end{array}$ \\
\hline 1.2.01.2 & $\begin{array}{l}\text { Título <title }>/ \\
\text { proyectos en red }\end{array}$ & [Texto] & $\begin{array}{l}\text { En productos codificados en HTML, etiqueta } \\
\text { <title> del apartado <head }>\text { del documento }\end{array}$ \\
\hline 1.2 .02 .1 & Autoría & [Texto] & $\begin{array}{l}\text { Responsabilidad del producto: autores, } \\
\text { distribuidores, productores, a título individual } \\
\text { o empresas, según proceda. Se Transcriben } \\
\text { los datos ofrecidos por los propios autores }\end{array}$ \\
\hline
\end{tabular}




\begin{tabular}{|c|c|c|c|}
\hline 1.2.02.2 & $\begin{array}{l}\text { Autoría <autor }>\text { / } \\
\text { proyectos en red }\end{array}$ & [Texto] & $\begin{array}{l}\text { En productos codificados en HTML, } \\
\text { etiqueta < author }>\text { del apartado } \\
<\text { head }>\text { del documento }\end{array}$ \\
\hline 1.2.03.1 & Metadatos & [Texto] & $\begin{array}{l}\text { Datos promocionales o descriptivos } \\
\text { ofrecidos por los propios autores }\end{array}$ \\
\hline 1.2.03.2 & $\begin{array}{l}\text { Metadatos } \\
<\text { meta }>/ \\
\text { proyectos en red }\end{array}$ & [Texto] & $\begin{array}{l}\text { En productos codificados en HTML, } \\
\text { los datos relevantes incorporados } \\
\text { en la etiqueta }<\text { meta }>\text { del apartado } \\
<\text { head }>\text { del documento }\end{array}$ \\
\hline 1.2 .04 & Dirección web & $\begin{array}{l}\text { [enlace } \\
\text { html] }\end{array}$ & Dirección/es electrónica de referencia \\
\hline 1.2.05.1 & Perfil en Facebook & [texto] & Nombre de perfil y/o dirección \\
\hline 1.2.05.2 & Perfil en Twitter & [texto] & Nombre de perfil y/o hashtag \\
\hline 1.2.05.3 & Perfil en Instagram & [texto] & Nombre de perfil y/o hashtag \\
\hline 1.2.05.4 & Perfil en Youtube & [texto] & Nombre de perfil y/o dirección \\
\hline 1.2.05.5 & Otros perfiles & [texto] & Nombre de perfil y/o dirección y/o hashtag \\
\hline 1.2 .06 & $\begin{array}{l}\text { Fecha de } \\
\text { lanzamiento }\end{array}$ & $\begin{array}{l}{[\mathrm{dd} / \mathrm{mm} /} \\
\text { aaaa] }\end{array}$ & $\begin{array}{l}\text { Indicar fecha de lanzamiento del producto. } \\
\text { En caso de no constar una fecha precisa, } \\
\text { puede consultarse el archivo de Archive.org }\end{array}$ \\
\hline 1.2.07 & $\begin{array}{l}\text { Estadio del } \\
\text { producto }\end{array}$ & [texto] & $\begin{array}{l}\text { Fase en la que se encuentra el producto: } \\
\text { prelanzamiento, activa, archivo u otras }\end{array}$ \\
\hline 1.2 .08 & Coste & [texto] & $\begin{array}{l}\text { Indicar si existe coste de adquisi- } \\
\text { ción o costes de subscripción }\end{array}$ \\
\hline 1.2 .09 & Idiomas & [texto] & Indicar el/los idioma/s de la aplicación \\
\hline 1.2 .10 & Otros & [texto] & $\begin{array}{l}\text { Indicar cualquier otro elemento descriptivo } \\
\text { que se considere importante reportar }\end{array}$ \\
\hline
\end{tabular}

Respecto al formato original de découpage interactivo, se han incorporado a esta versión de la herramienta indicadores relacionados con las redes sociales. También se ha añadido el parámetro 1.2.07 relativo a la fase temporal en la que se encuentra el interactivo. La mayoría de los productos transmedia actuales modifican su estado durante su desarrollo y permiten, por tanto, análisis puntuales y análisis longitudinales para poder, con ellos, apreciar su evolución.

Tabla 3. Módulo descriptivo. Apartado 1.3 Descripción y comprensión general

\begin{tabular}{|c|c|c|c|}
\hline \multicolumn{4}{|c|}{ 1. Módulo descriptivo } \\
\hline \multicolumn{4}{|c|}{ 1.3 Descripción y comprensión general } \\
\hline 1.3 .01 & Sinopsis & [texto] & $\begin{array}{l}\text { Descripción breve, de } 300-500 \text { palabras } \\
\text { en la que el analista describe de forma } \\
\text { general la aplicación. Es una descripción } \\
\text { subjetiva, en la que los distintos aspectos } \\
\text { que conforman el producto, la experiencia y } \\
\text { las percepciones de uso se entremezclan }\end{array}$ \\
\hline 1.3 .02 & $\begin{array}{l}\text { Descripción } \\
\text { contextual }\end{array}$ & [texto] & $\begin{array}{l}\text { Se describe el contexto de la aplicación: si } \\
\text { forma parte de algún programa, colección } \\
\text { o evento, si existen webs de soporte, etc. }\end{array}$ \\
\hline 1.3 .03 & $\begin{array}{l}\text { Uso principal } \\
\text { de la red }\end{array}$ & [texto] & $\begin{array}{l}\text { Indicar el grado de unidireccionalidad/ } \\
\text { bidireccionalidad del producto }\end{array}$ \\
\hline
\end{tabular}




\begin{tabular}{|c|c|c|c|}
\hline 1.3 .04 & $\begin{array}{l}\text { Usuarios-actores } \\
\text { /público }\end{array}$ & [texto] & Identificar los tipos de usuario potenciales \\
\hline 1.3.05 & $\begin{array}{l}\text { Usuarios-actores } \\
\text { / perfiles }\end{array}$ & [texto] & $\begin{array}{l}\text { Identificar los posibles perfiles de usuarios } \\
\text { que se contemplan: participante, colabo- } \\
\text { rador, co-creador, público, etc. }\end{array}$ \\
\hline 1.3.06 & Género & [texto] & $\begin{array}{l}\text { Confirmar el género aportado por los } \\
\text { autores (videojuego, documental, etc.) o } \\
\text { proponer una alternativa y justificarla }\end{array}$ \\
\hline 1.3.07 & Nivel de dificultad & [texto] & $\begin{array}{l}\text { Enumerar si el producto contempla } \\
\text { niveles de dificultad u otros procedi- } \\
\text { mientos que condicionen la lectura }\end{array}$ \\
\hline 1.3 .08 & Medio dominante & [texto] & $\begin{array}{l}\text { Enumerar los medios utilizados y } \\
\text { si hay un medio dominante }\end{array}$ \\
\hline 1.3 .09 & $\begin{array}{l}\text { Estrategia } \\
\text { transmedia }\end{array}$ & [texto] & $\begin{array}{l}\text { Se describen las estrategias transmedia } \\
\text { relacionadas con la aplicación: enlace } \\
\text { con redes sociales, participación de los } \\
\text { usuarios a través de otros medios, etc. }\end{array}$ \\
\hline 1.3.10 & Duración y fases & [texto] & $\begin{array}{l}\text { Previsión de duración del } \\
\text { proyecto y posibles fases }\end{array}$ \\
\hline 1.3.11 & $\begin{array}{l}\text { Aspectos } \\
\text { dominantes }\end{array}$ & [texto] & $\begin{array}{l}\text { Indicar aquellos aspectos que, desde una } \\
\text { valoración subjetiva se considera que diferen- } \\
\text { cian e identifican la aplicación y la distinguen }\end{array}$ \\
\hline 1.3.12 & $\begin{array}{l}\text { Evaluación } \\
\text { subjetiva }\end{array}$ & [texto] & $\begin{array}{l}\text { Apartado en el que el analista expone } \\
\text { aquellos aspectos que considera } \\
\text { destacables del producto }\end{array}$ \\
\hline 1.3.13 & $\begin{array}{l}\text { Objetivos para el } \\
\text { análisis orientado } \\
\text { en profundidad }\end{array}$ & [texto] & $\begin{array}{l}\text { Se apuntan los objetivos que se persigue } \\
\text { analizar en la segunda fase de análisis, } \\
\text { durante la lectura detallada del texto }\end{array}$ \\
\hline 1.3.14 & Hipótesis & [texto] & $\begin{array}{l}\text { Se apuntan posibles hipótesis sobre contenido, } \\
\text { ideología, discurso, formales o narrativos } \\
\text { que se pretende confirmar en la lectura }\end{array}$ \\
\hline 1.3.15 & $\begin{array}{l}\text { Filiaciones y } \\
\text { diálogos }\end{array}$ & [texto] & $\begin{array}{l}\text { Se indican aquellas obras con las que } \\
\text { se establecen diálogos -en forma de } \\
\text { filiaciones, cita o de género- con los } \\
\text { que se relaciona el texto analizado. }\end{array}$ \\
\hline
\end{tabular}

El tercer apartado comprende 10 indicadores relacionados con la identificación del producto y 5 con su comprensión y lectura, remarcados en color azul. Supone una modificación importante respecto al modelo de découpage utilizado para emular el guión original de las obras. En esta versión, adaptada a la comprensión lectora, se han añadido aspectos relacionados directamente con el close reading, como son la formulación de preguntas e hipótesis de lectura para una segunda lectura en detalle.

Para la segunda fase de lectura se contempla la selección y análisis de aquellos fragmentos que los lectores consideren significativos para obtener respuestas a sus preguntas de investigación. En función de aquello que se quiera analizar, resultará interesante ahondar en aspectos de contenido, estructura, interfaz o interacción, cada uno de los módulos en los que, tradicionalmente, se ha realizado el découpage de las obras. Es importante señalar la independencia de las distintas lecturas. La segunda fase de lectura puede realizarse teniendo en cuenta aspectos relacionados con la formulación del guión, con el découpage, o pude efectuarse a partir de otros métodos de análisis de texto, como son los análisis semióticos o los análisis por medio de marcos de referencia.

\section{Limitaciones del análisis}

A diferencia de las obras textuales o fílmicas, la experiencia y lectura de textos digitales interactivos se presenta fuertemente condicionada por su naturaleza digital y su codificación por medio de lenguajes de programación y su dependencia de los dispositivos y sistemas informáticos utilizados. La gran mayoría de trabajos audiovisuales interactivos desarrollados durante los años 80 y 90 del anterior 
siglo presentan enormes dificultades para poder reproducirse. La caducidad y obsolescencia tecnológica condiciona y deviene característica del medio, que precisa mutar de soporte, medio o tecnología para permanecer activo. Las tres obras elegidas para ilustrar este trabajo se han seleccionado expresamente porqué presentan distintas dificultades de observación que condicionan la realización de una lectura detallada completa.

Actualmente Rain Room (2012) sólo pueden consultarse en formato de archivo. Desde la web de Random International puede accederse a registros videográficos realizados durante la exposición de la pieza. Estos documentos permiten dimensionar e imaginar la experiencia de los usuarios que la exploraron in situ, en Londres, Nueva York o Shanghai. Se trata del registro editado de las lecturas que hicieron otros espectadores de la pieza. Por otra parte, si buscamos en Youtube o Vimeo otros registros de Rain Room, es fácil que localicemos otros registros, como el reportaje que realizó Oliver Wainwright para The Guardian (Wainwright, 2012) o el del coreógrafo y director teatral Wayne McGregor (2012).

La revisión de estos documentos traslada la lectura crítica a las fuentes secundarias, un escenario habitual en el ámbito del arte contemporáneo (Bonet et al., 1980). Con ello, se pone de manifiesto otras dimensiones sobre la autoría del analista, que amplifican el concepto de oscilación desarrollado por Bizzocchi y Tanenbaum (2011). La lectura crítica del objeto de estudio mediatizado permite una suerte de aproximación condicionada por la reconfiguración de la obra y la pérdida de parte de sus propiedades, como son, en este caso, la posibilidad de interactuar y de experimentar locativamente la obra. Sin embargo, estas pérdidas no desvirtúan la realización de una lectura en profundidad de la pieza como, efectivamente, la crítica de arte viene realizando respecto al arte efímero, las acciones y otras formas de creación archivadas a partir de sus registros fotográficos o videográficos.

Portrait One es consultable de forma completa en la versión editada el 1995 sobre formato CDROM por Artintact. Presenta algunas variaciones respecto a la versión expositiva, sobretodo en relación a la percepción locativa y contextual de la obra. A pesar de ello, puede considerarse que la versión publicada contempla todo el conjunto de la obra y que su lectura puede realizarse en su totalidad.

Homicide Watch D.C. permite prácticamente el análisis completo de la obra, si bien se trata de un producto que se encuentra discontinuado por parte de sus autores y puede considerarse en fase de archivo. El proyecto estuvo activo desde 2011 hasta el 31 de diciembre de 2014, momento en el que finalizó el mantenimiento y las actualizaciones por falta de recursos económicos (Amico, 2015). En un post publicado en Twitter el mismo día 31/12/2014, los autores explicitan el fin de la fase activa del proyecto y su paso a una fase de archivo: "Just so everyone>s clear, the site won>t *disappear* after today. We just won $>$ t have reporters in court or add new cases" (Homicide Watch DC, 2014).

Actualmente sólo presenta problemas de visualización el apartado [map], debido a la obsolescencia del recurso de programación (apis) utilizado para vincular los datos del archivo sobre los mapas de Google Maps. A pesar de ello, es interesante comprobar como distintos usuarios han publicado post en la web hasta el día de hoy, enero de 2019.

\section{Ejemplos de análisis}

\subsection{Fase inicial}

Se ha utilizado la obra Homicide Watch D.C. para ilustrar la aplicación del modelo de lectura detallada

en un caso concreto. A continuación, se presenta cumplimentada la ficha de análisis del módulo descriptivo.

Tabla 4. Ejemplo de aplicación del módulo descriptivo, apartado 1.1 Autoría y dispositivo de análisis para el análisis de la obra Homicide Watch D.C.

1. Módulo descriptivo

1.1 Autoría y dispositivo de análisis

\begin{tabular}{l|l|l}
\hline CODIGO & INDICADOR & CONTENIDO
\end{tabular}

\begin{tabular}{|l|l|l|}
\hline 1.1.01 & Fecha de análisis & 20/01/2019 \\
\hline 1.1.02 & Autońa & Pere Freixa
\end{tabular}




\begin{tabular}{|c|c|c|}
\hline 1.1 .03 & Filiación & Universitat Pompeu Fabra \\
\hline 1.1 .04 & Programa & $\mathrm{n} / \mathrm{c}$ \\
\hline 1.1 .05 & Dispositivo/s & $\begin{array}{l}\text { Dispositivo principal: Ordenador de sobremesa } \\
\text { con pantalla panorámica de } 1920 \times 1080 \text { píxeles. } \\
\text { Navegación por medio de teclado y ratón. } \\
\text { Dispositivo secundario: Smartphone Samsung } \\
\text { Note 3. Navegación por pantalla táctil. }\end{array}$ \\
\hline 1.1.06 & $\begin{array}{l}\text { Sistema operativo } \\
\text { y navegador }\end{array}$ & $\begin{array}{l}\text { Dispositivo principal: Windows 10. Navegador } \\
\text { Chrome, versión 71.0.3, de } 2019 . \\
\text { Dispositivo secundario: Android 5.0. } \\
\text { Navegador Chrome } 71.0 .3 \text {, de } 2019 \text {. }\end{array}$ \\
\hline 1.1.07 & $\begin{array}{l}\text { Capacidades } \\
\text { requeridas }\end{array}$ & $\begin{array}{l}\text { No requiere ningún dispositivo ni recurso adicional. } \\
\text { Tampoco precisa identificación. } \\
\text { Permite la subscripción. Cuando esta se realiza, se activa la } \\
\text { posibilidad de participar en el proyecto por medio de comenta- } \\
\text { rios. Estos se archivan en las entradas en que se han creado. }\end{array}$ \\
\hline 1.1.08 & Otras versiones & $\begin{array}{l}\mathrm{n} / \mathrm{c} \\
\text { El diseño se adapta a formato de la pantalla en el dispositivo móvil. }\end{array}$ \\
\hline 1.1.09 & Localización & Despacho, ámbito privado. \\
\hline 1.1.10 & Contexto de lectura & Lectura individual. \\
\hline
\end{tabular}

Tabla 5. Ejemplo de aplicación del módulo descriptivo, apartado 1.2 Datos identificativos para el análisis de la obra Homicide Watch D.C

\begin{tabular}{|c|c|c|}
\hline \multicolumn{3}{|r|}{ 1. Módulo descriptivo } \\
\hline \multicolumn{3}{|r|}{ 1.2 Datos identificativos } \\
\hline 1.2.01.1 & Título & $\begin{array}{l}\text { Homicide Watch D.C. Mark every death. Remember } \\
\text { every victim. Follow every case }\end{array}$ \\
\hline 1.2.01.2 & $\begin{array}{l}\text { Título }<\text { title }> \\
/ \text { proyectos } \\
\text { en red }\end{array}$ & $\begin{array}{l}<\text { title> Homicide Watch D.C. | Mark every death. } \\
\text { Remember every victim. Follow every case. }</ \text { title> }\end{array}$ \\
\hline 1.2.02.1 & Autoría & $\begin{array}{l}\text { En el apartado [about] "Who We Are" se presentan Chris Amico } \\
\text { y Laura Amico, periodistas y fundadores del proyecto. }\end{array}$ \\
\hline 1.2.02.2 & $\begin{array}{l}\text { Autoría } \\
<\text { autor }>/ \\
\text { proyectos } \\
\text { en red }\end{array}$ & $\begin{array}{l}<\text { meta name="author" content="Homicide Watch D.C."> } \\
<\text { meta property="og:title" content="Homicide Watch D.C." > }\end{array}$ \\
\hline 1.2.03.1 & Metadatos & Definen el proyecto como "a community-driven reporting project" \\
\hline 1.2.03.2 & $\begin{array}{l}\text { Metadatos } \\
<\text { meta }>/ \\
\text { proyectos } \\
\text { en red }\end{array}$ & $\begin{array}{l}<\text { meta name="description" content="Homicide Watch D.C. is a } \\
\text { community-oriented news site that aims to provide clear information } \\
\text { about homicides and the tools necessary to record, report and share } \\
\text { our experiences and losses within the District of Columbia." }> \\
<\text { meta property="og:type" content="blog"> } \\
<\text { meta property="og:site_name" content="Homicide Watch D.C." > }\end{array}$ \\
\hline 1.2 .04 & Dirección web & http://homicidewatch.org/index.html \\
\hline
\end{tabular}




\begin{tabular}{|c|c|c|}
\hline 1.2.05.1 & $\begin{array}{l}\text { Perfil en } \\
\text { Facebook }\end{array}$ & $\begin{array}{l}\text { Homicide Watch D.C. } \\
\text { https://www.facebook.com/Homicide-Watch-DC-121936297867647/ }\end{array}$ \\
\hline 1.2.05.2 & Perfil en Twitter & @homicidewatch y \#homicidewatch \\
\hline 1.2.05.3 & $\begin{array}{l}\text { Perfil en } \\
\text { Instagram }\end{array}$ & $n / c$ \\
\hline 1.2.05.4 & $\begin{array}{l}\text { Perfil en } \\
\text { Youtube }\end{array}$ & $\begin{array}{l}\text { HomicideWatch } \\
\text { https://www.youtube.com/channel/UCbLyUB_S9wuxCIDtoYcszYw }\end{array}$ \\
\hline 1.2.05.5 & Otros perfiles & Posibilidad de sindicación (RSS) con FeedBurner \\
\hline 1.2 .06 & $\begin{array}{l}\text { Fecha de } \\
\text { lanzamiento }\end{array}$ & $\begin{array}{l}\text { Septiembre de } 2010 \text {. Primer registro en Archive. } \\
\text { org: } 30 \text { diciembre de } 2010 .\end{array}$ \\
\hline 1.2 .07 & $\begin{array}{l}\text { Estadio del } \\
\text { producto }\end{array}$ & $\begin{array}{l}\text { En diciembre de } 2014 \text { el producto de discontinua, pasando } \\
\text { a un estado de archivo. Sin embargo, los usuarios han } \\
\text { seguido publicando posts y comentarios hasta } 2019 \text {. }\end{array}$ \\
\hline 1.2 .08 & Coste & $\begin{array}{l}\text { Sin costes. Consulta en abierto en Internet. } \\
\text { Apartado para la realización de donativos. }\end{array}$ \\
\hline 1.2 .09 & Idiomas & Lengua inglesa. \\
\hline 1.2 .10 & Otros & $\begin{array}{l}\text { Dirección de correo electrónico para contactar con los autores. } \\
\text { Tour visual de presentación del proyecto en formato } \\
\text { vídeo, publicado en la web y en Youtube. }\end{array}$ \\
\hline
\end{tabular}

Tabla 6 Ejemplo de aplicación del módulo descriptivo, apartado 1.3 Descripción y comprensión general para el análisis de la obra Homicide Watch D.C

\section{Módulo descriptivo}

\subsection{Descripción y comprensión general}

1.3.01 Sinopsis $\quad$ Proyecto informativo independiente, que puede considerarse de periodismo estructurado, en el que se recopilan todas las informaciones (legales, de prensa, de redes sociales, periodísticas y de publicaciones en redes sociales) relacionadas con los delitos de asesinato sucedidos en el Distrito de Columbia, Washington DC. Se trata de un proyecto que, como sus autores defienden "creemos que la forma en que las personas viven y mueren aquí, y cómo se reconocen esas muertes, importa a todos.

Si importa cómo es asesinado alguien en Cleveland Park, entonces tambien importa cómo muere alguien en Truxton Circle, lvy City, Washington Highlands o Georgetown. Si queremos entender los delitos violentos en nuestra comunidad, las pérdidas de cada familia, en cada vecindario, deben ser reconocidas. Y el resultado de cada juicio, ya sea una condena o una absolución, debe registrarse".

Proyecto en formato web, con continuidad en las redes sociales. Se organiza a partir de 9 apartados, agrupados en dos bloques. El primero, formado por las opciones [Last news], Victims], [Suspects] y [Map]. El segundo por [Photos], [Documents], [Calendar], [Comments Policy] y [About]. Los acontecimientos, los asesinatos, se organizan a partir de las personas implicadas y el lugar de los hechos. El lugar se geolocaliza en un mapa de Google maps, sobre el que se van situando el conjunto de incidentes.

Se accede a él por medio de la opción [Map]. [Last news] presenta en pantalla los últimos acontecimientos entrados en el sistema, ordenados de más reciente a más viejo. Nictims] y [Suspects] dan acceso al listado de víctimas y sospechosos implicados en los asesinatos. Dos opciones son informativas: [About] y [Comments Policy]. La primera ofrece información sobre el proyecto y la segunda sobra la regulación para añadir comentarios. [Photos], [Documents] y [Calendar] permiten el acceso a las fuentes primarias del proyecto, los documentos y su organización temporal. 
Se accede a él por medio de la opción [Map]. [Last news] presenta en pantalla los últimos acontecimientos entrados en el sistema, ordenados de más reciente a más viejo. [Victims] y [Suspects] dan acceso al listado de víctimas y sospechosos implicados en los asesinatos. Dos opciones son informativas: [About] y [Comments Policy]. La primera ofrece información sobre el proyecto y la segunda sobra la regulación para añadir comentarios. [Photos], [Documents] y [Calendar] permiten el acceso a las fuentes primarias del proyecto, los documentos y su organización temporal.

Todas las entradas publicadas permiten comentarios. Algunas informaciones han generado colas de comentarios bastante extensos, en algunos casos, entre detractores y defensores de victimas y acusados. Los post están publicados mayoritariamente por los autores del proyecto, aunque existen otras voces. En algunas ocasiones, los autores actúan como moderadores en los hilos de intervenciones y comentarios. El mapa resultante dibuja una suerte de escenario de peligrosidad de Washington.

1.3.02 Descripción Los autores asocian el proyecto a una "red de sedes contextual dedicadas al seguimiento de homicidios en Estados Unidos de América". En los créditos no consta ninguna organización, empresa o fundación que dé cobertura al proyecto.

1.3.03 Uso principal Proyecto web bidireccional, con pautas y roles de diálogo diferenciadas entre de la red los distintos actores participantes. Edición y creación de contenido unidireccional por parte de la autoría principal del proyecto y posibilidad de diálogos por medio de las redes sociales y la publicación de posts previa identificación.

1.3.04 Usuarios- Se detectan dos categorías de usuarios potenciales: público general, actores / interesado en la temática y público implicado, por vínculo con público alguno de los personajes involucrados, por vecindad, pertenencia en instituciones relacionadas, trabajadores sociales, etc.

1.3.05 Usuarios- Se detectan 4 categorías: 1) autores del proyecto. Dinamizan, publican actores / post, gestionan perfiles y mantienen el proyecto activo. moderan

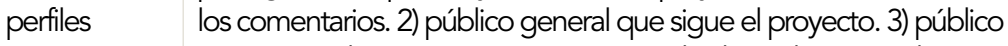
que se suscribe para tener seguimiento de algún determinado caso 4) público participante, por medio de posts y comentarios.

1.3.06 Género Proyecto de periodismo comunitario. Trabajo de dinamización de dinámicas sociales por medio del periodismo y el diálogo con la comunidad.

1.3.07 Nivel de Alfabetismo informacional básico. No contempla niveles de dificultad. dificultad

1.3.08 Medio Texto y mapa. El proyecto se basa en las informaciones textuales que dominante publican periódicamente los autores. El mapa, un recurso aparentemente neutro, deviene una potente herramienta para el debate político local, al evidenciar la distribución de la violencia sobre el teritorio.

1.3.09 Estrategia Peso principal del proyecto web en Internet. Los perfiles en transmedia las redes sociales permiten la promoción, el diálogo con otros actores y la recopilación de información. Canal de Youtube usado como archivo de documentos videográficos.

1.3.10 Duración Proyecto en fase activa desde septiembre de 2010 hasta y fases diciembre de 2014. Actualmente en fase de archivo. Acceso activo en la red y mantenimiento discontinuado.

1.3.11 Aspectos El proyecto permite el acceso tanto a la información ofrecida por los dominantes autores como a documentos policiales, actas e informes sobre los casos. El trabajo periodístico se sustenta con la posibilidad de consultar las fuentes originales de información. Se permite también el debate sobre los materiales, por medio de comentarios y posts publicados por otros usuarios. Sobresale la larga durabilidad del proyecto. 


\begin{tabular}{|c|c|c|}
\hline 1.3.12 & $\begin{array}{l}\text { Evaluación } \\
\text { subjetiva }\end{array}$ & $\begin{array}{l}\text { El proyecto pretende dar visibilidad a todos los asesinatos que suceden } \\
\text { en Washington, sede de la capital de Estados Unidos. Se proyecta } \\
\text { como una potente herramienta de debate social, con impacto en } \\
\text { ámbitos distintos, como la educación, las políticas locales, etc. } \\
\text { Presenta un formato novedoso como género periodístico, al ubicar los } \\
\text { procesos de información fuera del ámbito de los medios de comunicación. }\end{array}$ \\
\hline 1.3.13 & $\begin{array}{l}\text { Objetivos } \\
\text { para el } \\
\text { análisis } \\
\text { orientado en } \\
\text { profundidad }\end{array}$ & $\begin{array}{l}\text { 1) comprobar si el sistema vincula las informaciones con otros } \\
\text { medios de comunicación y si ese vínculo es recíproco. } \\
\text { 2) Analizar el uso de imágenes fotográficas en el } \\
\text { proyecto. Categoría y funcionalidad. } \\
\text { 3) A partir de un caso, reseguir la relación entre documentos } \\
\text { originales, posts publicados y diálogos mantenidos con } \\
\text { usuarios para intentar valorar el peso de los documentos y } \\
\text { datos en el diálogo y argumentación de los participantes. } \\
\text { 4) Observar la estructura y archivo de los comentarios de los usuarios. } \\
\text { Comprobar qué categorización se da a los aportes de los usuarios. }\end{array}$ \\
\hline 1.3.14 & Hipótesis & $\begin{array}{l}\text { El proyecto presenta un potencial importante como herramienta de dinamiza- } \\
\text { ción de debates sobre peligrosidad, responsabilidad social, uso de armas, } \\
\text { diferencias sociales y étnicas, permanencia de problemas étnicos, etc. } \\
\text { Se propone buscar referentes del proyecto en redes sociales, ONGs, } \\
\text { institutos de secundaria, prensa, política local, etc., para comprobar si, } \\
\text { efectivamente, el proyecto ha tenido repercusión social efectiva. }\end{array}$ \\
\hline 1.3.15 & $\begin{array}{l}\text { Filiaciones } \\
\text { y diálogos }\end{array}$ & $\begin{array}{l}\text { El trabajo parece fundamentarse con proyectos interactivos similares, como } \\
\text { Chicagocrime.org, de Holovarty, publicado durante el período 2005-8, } \\
\text { aunque, en Homicide Watch DC, los autores expanden el mashup con } \\
\text { capas de información periodística que añaden discurso al proyecto. } \\
\text { El proyecto Homicide Watch Chicago supone una réplica de este } \\
\text { proyecto, aunque bajo el auspicio de Chicago Sun-Times. }\end{array}$ \\
\hline
\end{tabular}

\subsection{Ejemplo de análisis detallado}

Para ejemplificar la segunda fase de análisis se muestra el resultado de la lectura realizada para dar respuesta al objetivo 4 formulado en el indicador 1.3.13., con el siguiente enunciado: "Observar la estructura y archivo de los comentarios de los usuarios. Comprobar qué categorización se da a los aportes de los usuarios".

En primer lugar, se han localizado todas las interfaces en las que aparecen comentarios de los usuarios. Estas son dos: la interfaz principal, la que actúa como Homepage (Figura 4), y la interfaz que se presenta en pantalla cuando accedemos a cualquier post, ya sea desde la opción [Victims], [Suspects], [Map] o [Photos] (Figura 5). Se ha observado que el proyecto utiliza la aplicación Disqus (disqus.com) como plataforma para el archivo de posts y comentarios de usuarios. Cuando se activa el nombre de un usuario en el apartado de comentarios, abandonamos la aplicación y accedemos al espacio de HomicideWatch en Disqus (Figuras 7 y 8).

Los autores del proyecto participan en los diálogos entre los usuarios, básicamente para agradecer informaciones, clarificar nombres y datos o corregir errores detectados por otros usuarios, como puede comprobarse en la Figura 6. En otros casos, las intervenciones sirven para ampliar información relacionada con algún aspecto concreto del caso.

Puede considerarse que existe una categorización marcada entre las informaciones que forman parte de lo que podríamos llamar el corpus principal del proyecto, los posts periodísticos, los documentos digitalizados, el mapa y las fotos y lo que son materiales de usuarios, que se gestionan por medio de una aplicación externa, vinculada al medio. La relación a nivel de interfaz entre las dos aplicaciones resulta transparente para el usuario: el registro, así como la publicación de posts, se realiza en HomicideWatch y se 


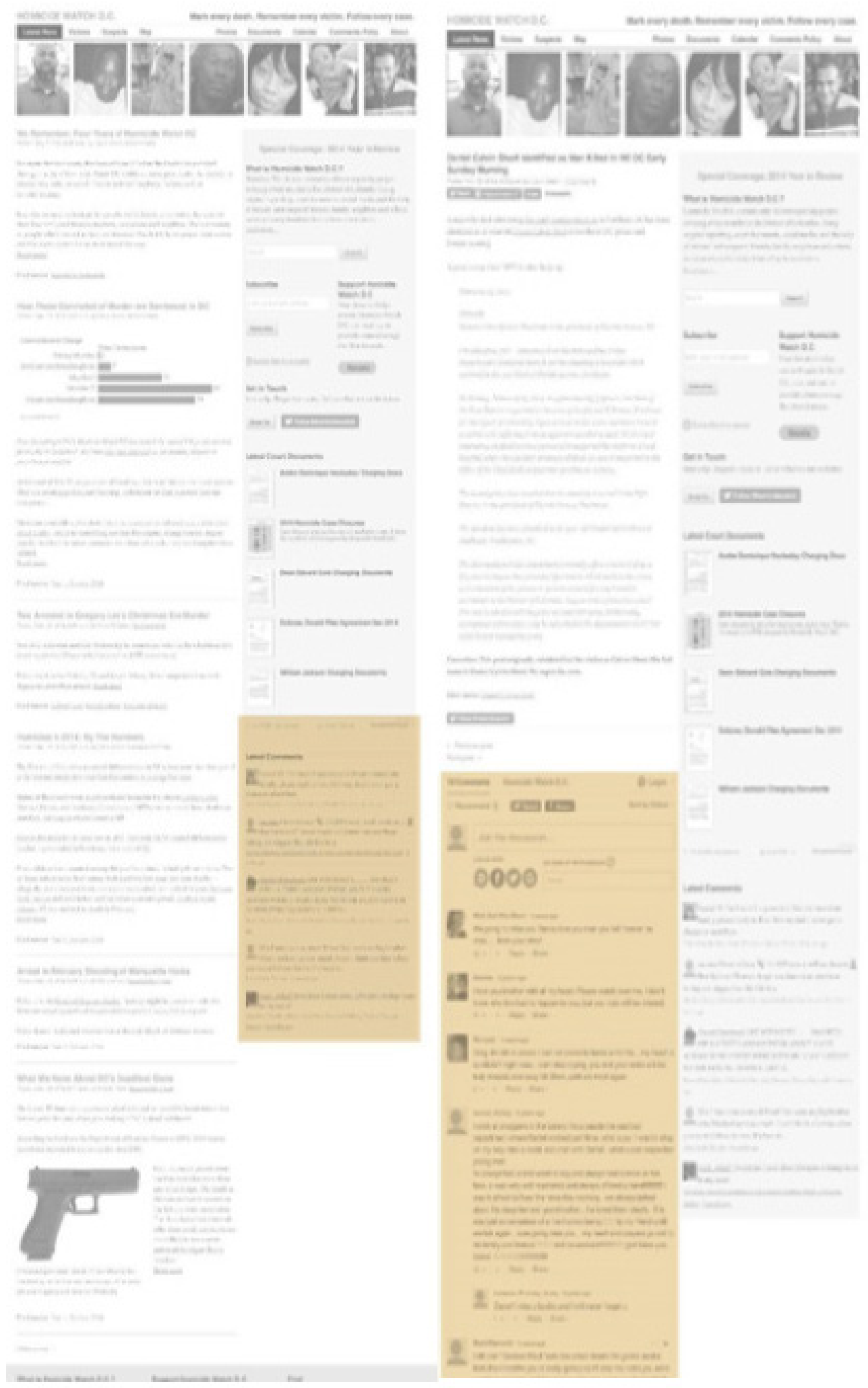

Figuras 4 y 5 . Homicide Watch D.C. Página principal en la que se ha remarcado el espacio destinado a comentarios de los usuarios. Página de post con los comentarios publicados. Elaboración propiaindex.html 
R.P. Danny you wall be forever missed

IA * Reply shere.

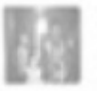

I work at shoppers in florel I well miss your kindness and that beautilu smile you were a joy to work with you will truly be missed. God bless your family.

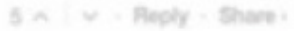

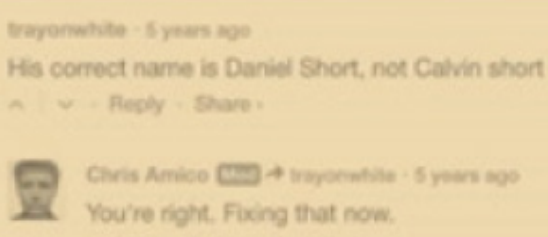

Figura 6. Homicide Watch D.C. Recuperado de: http:// homicidewatch.org/index.html

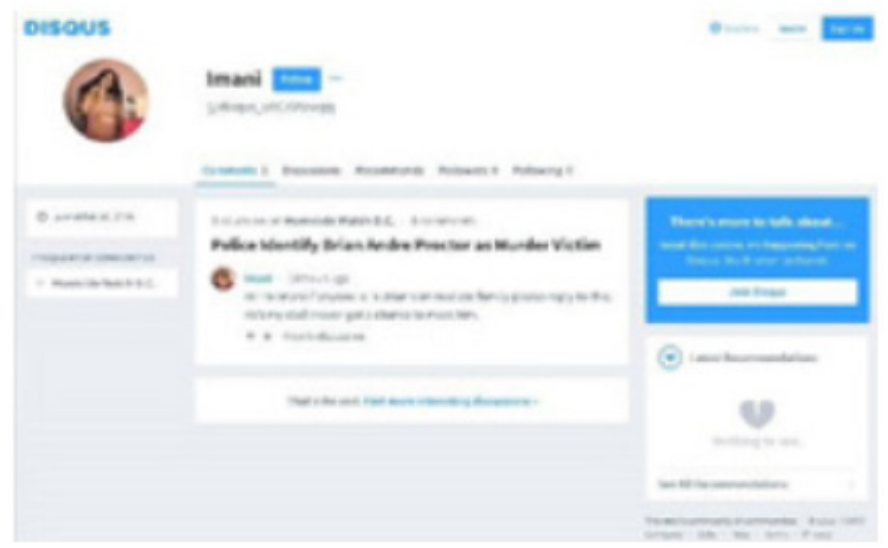

Figura 7. Homicide Watch D.C. Pantallas correspondientes a los diálogos mantenidos por usuarios a través de la aplicación Diqus. Elaboración propia.

almacenan en el fórum creado en Diqus.

La página principal del fórum Homicide Watch DC en Diqus permite revisar todos los comentarios, usuarios participantes y diálogos mantenidos (Figura 9).

Los comentarios publicados por Laura Amico y Chris Amico, autores del proyecto, permiten comprobar el seguimiento que realizan sobre todos los casos. Como moderadores, no parecen intervenir en los diálogos entre usuarios, sobre todo cuando se enfrentan víctimas y acusados. A pesar de que moderan los comentarios que se publican, algunos provocan controversia con el resto de los usuarios. En el post publicado en 2012 sobre el caso de Reynaud Cook, a propósito de una queja de un usuario, Laura Amico argumenta: "Es una línea muy fina entre lo que cumple los criterios de publicación y lo que no. Siempre partimos del supuesto de que se debe publicar un comentario porque fomentamos el diálogo desde una variedad de puntos de vista y experiencias, incluidos aquellos con los que ambos estamos de acuerdo y con los que no estamos de acuerdo. No publicamos

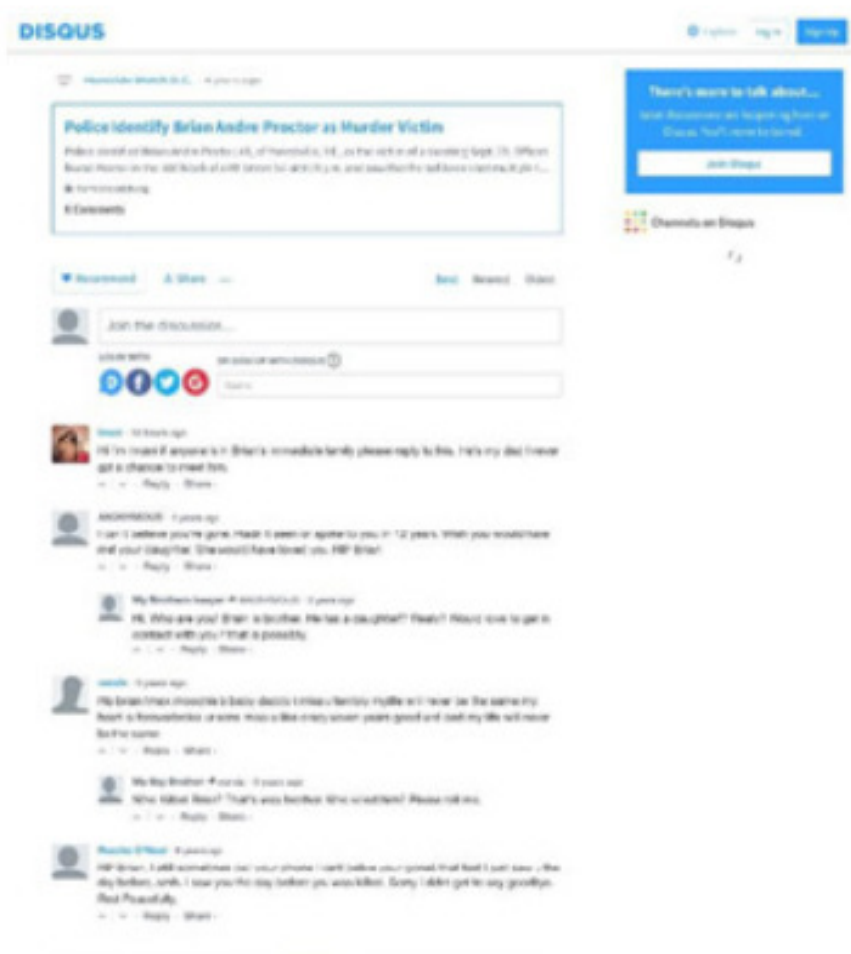

Figura 8. Homicide Watch D.C. Pantallas correspondientes a los diálogos mantenidos por usuarios a través de la aplicación Diqus. Elaboración propia.

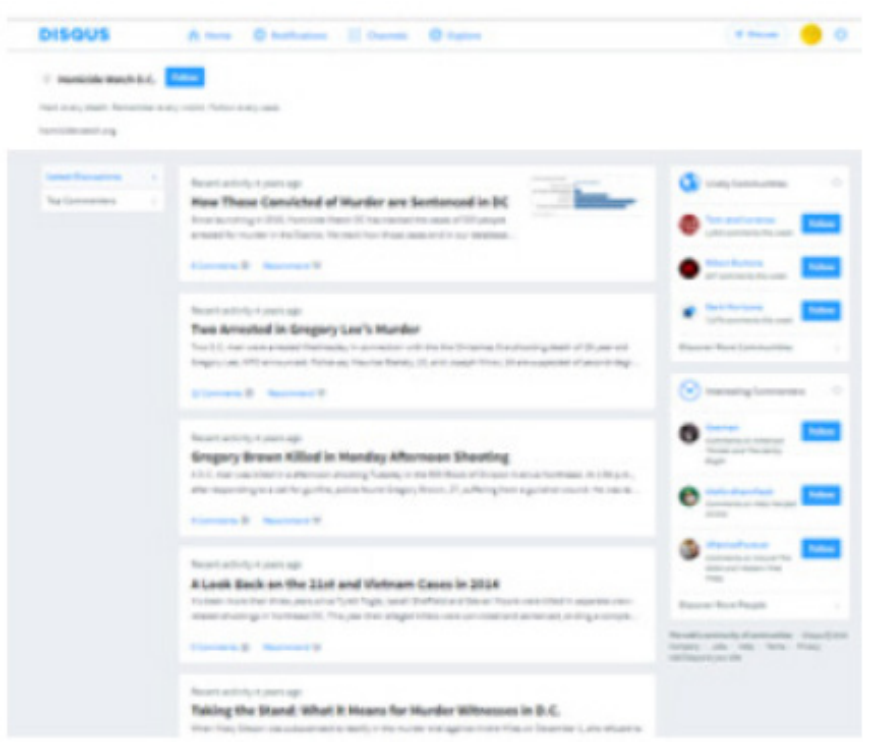

Figura 9. Pantalla correspondiente al fórum de Homicide Watch DC creado en Diqus. Elaboración propia.

comentarios que sean vulgares, obscenos, constituyan una amenaza o sean un ataque personal" (Amico, 2012).

\section{A modo de conclusiones}

Como apuntan Bizzocchi y Tanenbaum, "La lectura es un proceso continuo de creación de significado contingente a partir del significado potencial « (2011, 
p.2). El modelo de lectura detallada, de lectura en profundidad que se presenta busca aproximar al lector a los distintos aspectos que configuran una obra interactiva. Por medio de los indicadores propuestos, se propone acercar la lectura a los procesos de codificación, organización de contenidos y narrativa que los autores establecen en cada obra.

Se parte del análisis descriptivo de los diferentes aspectos que caracterizan la obra. A partir de la formulación de los objetivos de investigación que han motivado el interés del lector, se procede a profundizar en el análisis detallado. Este puede ahondar tanto en aspectos discursivos, simbólicos como retórico-narrativos. El sistema propuesto no condiciona los posibles análisis que desee realizar el investigador.

En entornos educativos, la práctica del close reading propone, a menudo, una tercera etapa de confrontación de resultados en grupo, en que se comparten las percepciones y resultados obtenidos en los análisis individuales.

El análisis de fragmentos permite focalizar el interés de la observación en un objetivo determinado. Estos análisis fragmentados pueden complementarse con análisis globales de aspectos propios de los productos interactivos, como son los análisis de interfaz, el mapa de navegación o el estudio de la interactividad.

\section{Bibliografía citada y consultada}

Aarseth, E. (1997). Cybertext. Perspectives on Ergodic Literature. Baltimore, Maryland: The Johns Hopkins University Press.

Amico, L. (28 de junio de 2012). Reynaud cook Charged in Shooting of Yolanda Stone. Homicide Watch D.C. Recuperado de http://homicidewatch.org/2012/06/28/reynardcook-charged-in-shooting-of-yolanda-stone/index.html

Amico, C.; Amico, L. (2011). About Homicide watch D.C. Homicide watch D.C.

http://homicidewatch.org/about

Amico, L. (7 de mayo de 2015). We remember: Four years of Homicide watch DC. Homicide watch D.C. Recuperado de http://homicidewatch.org

Bizzocchi, Jim; \& Tanenbaum, Joshua (2011). Well Read: Applying Close Reading Techniques to Gameplay Experiences. In: Davidson, Drew (ed.). Well Played, 3.0, ETC Press, p. 262-290. DOI: 10.1184/R1/6687050

Bonet, E., Dols, J., Mercader, A., y Muntadas, A. (eds). (1980). En torno al vídeo. Barcelona: Gustavo Gili, Barcelona.

Brooker, W. (2001). The many lives of the Jetman: A case study in video game analysis. Intensities: The journal of cult media, (2). Recuperado de https://intensitiescultmedia. files.wordpress.com/2012/12/brooker-many-lives-of-thejetman.pdf

Burke, B. (2015). Guided Reading or Close Reading. The Write fix. Recuperado de: http://baburke.edublogs. org/2015/05/26/guided-reading-or-close-reading/

Burke, B. (2012). A Close Look at Close Reading: Scaffolding Students with Complex Texts. Recuperado de: https:// nieonline.com/tbtimes/downloads/CCSS_reading.pdf

Carr, D. (2009). Textual Analysis, Digital Games, Zombies. Proceedings of DiGRA 2009: Breaking New Ground: Innovation in Games, Play, Practice and Theory. Recuperado de http://www.digra.org/digital-library/publications/ textual-analysis-digital-games-zombies /

Cavell, S. (1999) La búsqueda de la felicidad. La comedia de enredo matrimonial en Hollywood. Barcelona: Paidós. [Versión original: Cavell, S. (1981). Pursuits of Happiness. The Hollywood Comedy of Remarriage. Cambridge, Massachusetts: Harvard University Press].

Common Core State Standards Initiative (2019). About the Standards. Recuperado de: http://www.corestandards.org/ about-the-standards

Consalvo, Mia, \& Dutton, Nathan (2006). Game Analysis: Developing a Methodological Toolkit for the Qualitative Study of Games. Game Studies The International Journal of Computer Game Research, 6(1).

Courchesne, Luc (1988). Portrait One. ADA. Archive of Digital Art. https://www.digitalartarchive.at/database/ general/work/portrait-one.html

Csikszentmihalyi, M. (1990). Flow. The Psychology of Optimal Experience. New York: Harper Perennial.

Freixa, P., Pérez-Montoro, M., y Codina, L. (2017). Interacción y visualización de datos en el periodismo estructurado. El profesional de la información, 26(6), 1076-1090. doi:10.3145/epi.2017.nov.07

Freixa, P. (2015). Reportajes especiales en los cibermedios. Análisis de diez años de Premios Goya y Oscar Awards en Elpais.com (2005-2014). El profesional de la información, 24(3), 291-300. doi:10.3145/epi.2015.may.09

Freixa. Pere; Soler-Adillon, Joan; Sora, Carles; Ribas, J. Ignasi (2014). Aportaciones del découpage interactivo en la lectura y análisis de audiovisuales interactivos de los cibermedios. Hipertext.net, (12). doi: 10.2436/20.8050.01.2

Freixa, P. (2009). Modelo para el découpage de audiovisuales interactivos. Recuperado de http://hdl.handle. net $/ 10230 / 16197$

Fürsich, Elfriede (2009). In defense of textual analysis. Restoring a challenged method for journalism and media studies. Journalism Studies, 10, (29), 238-252.

\section{DOI: $10.1080 / 14616700802374050$}

Homicide Watch DC (31 de diciembre de 2014). Twitter post. Recuperado de https://twitter.com/homicidewatch/ status/550292669050920962

Jenkins, H, Ford, S, Green, J (2013). Spreadable Media: Creating Value and Meaning in a Networked Culture. New York: New York University Press. 
Lapp, D., Moss, B., Grant, N., y Johnson, K. (2015). A Close

Look at Cloose Reading. Teaching students to analize complex texts, grades K-5. Alexandria, VA: ASCD.

Lexile (2019). About Lexile Measures. Recuperado de: https://lexile.com/education-companies/about-lexile-measures /

Manovich, L. (2001). The Language of New Media.

Cambridge, Massachusets: The MIT Press.

McGregor, W. (2012). Ramdom Dance in the Rain Rom [video]. Recuperado de https://vimeo.com/54092039

Rafaeli, Sheizf (1988). From New Media to Communication.

Sage Annual

Review of Communication Research: Advancing Communication Science 16:

110-134.

Ribas, J.I. (2001). Difusió cultural i comunicació audiovisual interactiva. Temes de disseny, (18), 170-204. Recuperado de http://tdd.elisava.net/coleccion/18/ribas

Ribas, J.I, y Freixa, P. (1997). Disseny interactiu, una especialitat central en la producció de sistemes interactius multimèdia. Treballs de comunicació, (8), 19-37. Recuperado de http://www.raco.cat/index.php/TreballsComunicacio/

article/view/243117

Ryan, M.-L. (2001). Narrative as Virtual Reality. Baltimore, Mariland, USA: Johns Hopkins University Press

Soler-Adillon, J., Sora, C., Freixa, P., y Ribas, J.I. (2016). Perfil del profesional de la comunicación interactiva: fundamentos, actualidad y perspectivas. El profesional de la información, 25 (2), 196-208.

Soler-Adillon, J. (2015). The intangible material of interactive art: agency, behavior and emergence. Artnodes, (16), 46-52.

Sweeney, Sabrina (October, 4, 2012) Exhibition gives visitors power to control the rain. BBC News, https://www.bbc. com/news/entertainment-arts-19827066.

Van Looy, Jan; \& Baetens, Jan (ed.) (2003). Close Reading New Media: Analyzing Electronic Literature. Leuven (Belgium): Leuven University Press

Wainwright, O. (4 de octubre de 2012). Barbican>s Rain Room: it>s raining, but you won>t get wet. The Guardian. [Video]. Recuperado de https://youtu.be/EkvazIZx-F0 

ISBN 978-84-09-20524-0

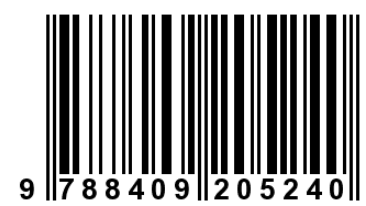

Máster Universitario en Investigación en Comunicación Social (MUCS)

\begin{tabular}{l|ll}
$\mathbf{u} p f$. & $\begin{array}{l}\text { Universitat } \\
\text { Pompeu Fabra } \\
\text { Barcelona }\end{array}$ & $\begin{array}{l}\text { DIGIDOC Grup de Recerca } \\
\text { en Documentació Digital } \\
\text { i Comunicació Interactiva }\end{array}$
\end{tabular} 